\title{
Predicting risk habitats for the transmission of the small liver fluke, Dicrocoelium dendriticum to grazing ruminants
}

\author{
Börje Ekstam¹, Beatha Johansson², Patrik Dinnétz ${ }^{3}$, Patrik Ellström ${ }^{2,4}$ \\ ${ }^{1}$ School of Natural Sciences, Linnaeus University, SE-39182 Kalmar, Sweden; ${ }^{2}$ Section for Zoonotic Ecology and \\ Epidemiology, School of Natural Sciences, Linnaeus University, SE-39182 Kalmar, Sweden; ${ }^{3}$ School of Life \\ Sciences, Södertörn University, SE-14189 Huddinge, Sweden; ${ }^{4}$ Clinical Bacteriology, Department of Medical \\ Sciences, Uppsala University, SE-75185 Uppsala, Sweden
}

\begin{abstract}
A multiple regression model was used to analyse if the structure of vegetation and soil patches in grazed units (pastures) can be used as explanatory variables to predict the prevalence of Dicrocoelium dendriticum, a common parasite of cattle and sheep, in grazing cattle stocks on the Baltic island of Öland in southern Sweden. The scale dependency was evaluated by comparing three levels of spatial resolution of patches. Prevalence data were obtained from slaughtered animals. Our models predict that the prevalence of $D$. dendriticum increases in grazed areas with woody vegetation, whereas moist and wet areas decrease parasite prevalence. The predictive power of the statistical models increased with increasing level of patch resolution. Approximately $42 \%$ of the variation in parasite prevalence (angular transformation) was explained by the areal proportion of vegetation types $\left(4^{\text {th }}\right.$-root-transformed). Based on the results obtained, we believe that our model strategy provides a rational and systematic tool to identify habitats that carry risk for D. dendriticum infection of ruminants, and that it can be applied to other parasites with similar life cycles such as Fasciola hepatica.
\end{abstract}

Keywords: cattle, vegetation type, parasite transmission, multiple regression, landscape ecology.

\section{Introduction}

Various species of the small liver fluke Dicrocoelium are common parasites of cattle and sheep. Their lifecycles involve two invertebrate intermediate hosts. They infect gall bladder and bile ducts, mainly in ruminants, but they can also infect pigs, horses, dogs and occasionally even humans. The disease is mostly asymptomatic, but can in severe cases lead to anaemia, and emaciation (Otranto and Traversa, 2003). It is one of the leading causes of discarding liver for health reasons in Sweden (from sheep as well as from cattle).

$D$. dendriticum is present throughout Europe and several studies have reported prevalence data for this fluke in ruminants and wild animals in different parts of Europe (Otranto and Traversa, 2002). It is mainly found in dry calcareous areas, but little is known about regional and local variations in distribution or the risk for parasite transmission to grazing ruminants in different habitats. A comparison of prevalence studies reveals large variations, both between regions and at smaller scales. A few studies suggest that this variation

Corresponding author:

Patrik Ellström

Clinical Bacteriology, Department of Medical Sciences

Uppsala University, SE-75185 Uppsala, Sweden

Tel. +46 18 611-3764; Fax +46 18 55-9157

E-mail: Patrik.Ellstrom@medsci.uu.se is due to landscape structures such as soil distribution and vegetation types, among others. Chartier and Reche (1992) concluded that the presence of D. lanceolatum (syn. D. dendriticum) in dairy goats in their study area in western France was related to calcareous alkaline soils. A high percentage of wood, rocks and arable soil with sparse trees explained the spatial distribution of $D$. dendriticum in sheep from southern Italy (Cringoli et al., 2002; Musella et al., 2011).

Considering that the $D$. dendriticum life cycle is complicated and involves two intermediate hosts with specific habitat requirements, it is not surprising that differences in prevalence seem to be related to landscape factors (Manga-Gonzalez et al., 2001). The eggs of the parasite are released with the faeces of the definitive host and infect land mollusks (the first intermediate host) feeding on these excrements. Mature cercariae, excreted from the mollusk in mucilaginous clusters are particularly attractive for ants as food. After ingestion by this second intermediate host, the parasite develops further, ultimately taking control of the ant behaviour in a way that completes the life cycle by facilitating spread to the definitive host. Several ant and mollusk species serve as intermediate hosts (Manga-Gonzalez et al., 2001). However, these different host species are confined to specific habitats and the distribution of $D$. dendriticum must therefore be limited to habitats where the host distributions coin- 
cide. Water availability, soil type and vegetation are important habitat factors, both for ants and mollusks as they relate to various parasite requirements. Examples include fine-grained structures like speciesspecific differences in closely related plant communities, and course-grained structures such as forests and open grasslands. Identification of risk habitats, i.e. areas where parasite infection of ruminants are particularly common, can help farmers avoid high-risk pastures. Alternatively, they may attempt to reduce the abundance of these parasites by managing certain landscape structures.

The aim of this study was to identify habitats carrying high risk for $D$. dendriticum infection of cattle, building on the hypothesis that the effect of landscape structures (e.g. lake, arable land or forest) on the relative prevalence of the parasite is scale-dependent. However, the many variables involved for each structure, e.g. with regard to forest, the type (coniferous, broadleaved, etc.) and its humidity (dry, moist or wet), underline the need to find the appropriate impact to be able to analyse the $D$. dendriticum risk. To that end, we employed multiple regression models to identify soil and vegetation types in grazed areas that significantly predict the prevalence of $D$. dendriticum in grazing cattle stocks. We evaluated the scale-dependency by comparing three levels of spatial resolution of a type of patch vegetation.

\section{Materials and methods}

The prevalence of $D$. dendriticum in cattle stocks at 203 farms on the island of Öland, a large Swedish island in the southern Baltic, was analysed as a function of soil and vegetation type. All prevalence data were obtained from surveillance of livers from animals slaughtered at the abattoir of KLS Ugglarps AB, Kalmar, Sweden. The helminths were not differentiated further than the genus, i.e. Dicrocoelium spp. but D. dendriticum is the dominating species in Sweden (personal communication, Dr Dan Christensson, Swedish National Institute of Veterinary Medicine). The data included all farms with more than 10 animals slaughtered per year, for at least four years during the period of 2000-2007.

The continuous response variable, parasite prevalence, was analysed in linear multiple regression models using a set of explanatory variables containing the proportion of different landscape types for all farms at three different levels of patch resolution. A patch is defined as a relatively homogeneous area in the landscape that differs from its surroundings (Forman,
1995). Data on grazing areas were extracted from the county board register of applications for environmental support to semi-natural grasslands (SAM-applications). Each application lists grazed areas as digitized "block maps" (scale 1:10,000). These maps are based on aerial photographs with layers showing farms and blocks of agricultural usage. All maps were provided by the County Board Administration, located in Kalmar, Sweden. For each farm, blocks used for grazing were merged into one area and this map further merged with the Geographical Swedish Data map (GSD-map ${ }^{\mathrm{TM}}$ ) of vegetation types on Öland (Wallner, 1999), exemplified in Figure 1. A local quaternary deposits map data, provided by the Geological Survey of Sweden authority (SGU), was also used together with the 1997-1999 vegetation map (vegetation type resolution of $0.25-1 \mathrm{ha}$ ), provided by the Swedish mapping, cadastral and land registration authority (Lantmäteriet, 2009). Spatial measurements were made with ArcGIS 9 and ArcMap version 9.2 (ESRI, Redlands, CA, USA). Based on the data as "attributes", applying the tools "intersect" and "dissolve", we estimated the areas of the vegetation and soil types at each farm. In this study, the classification of vegetation follows the system used in the national GSD-vegetation map.

All statistical analyses were performed with the statistical package R (R Development Core Team, 2010). The prevalence $(p)$ of parasites among slaughtered animals for a single stock was calculated as the average proportion over the 8 -year period. All prevalence data were transformed into angles with arcsin before analysis (Sokal and Rohlf, 1995).

The effect of different vegetation types on $D$. dendriticum prevalence was analysed in three separate multiple regression models, representing different degrees of patch resolution based on the vegetation classification in the national GSD-maps (Fig. 1), i.e. the "landscape type", the "main vegetation type" and the "vegetation type". The former are large-scale patterns such as surface water, shrub vegetation and forest, while the "main vegetation types" correspond to the next level of resolution, i.e. the kind of forest (mixed deciduous forest, coniferous forest of the bryophyte type, etc.). The "vegetation type" represents a still higher resolution (e.g. the coniferous forest of the bryophyte type can be divided into eight different categories ranging from very dry to extremely wet).

The different "vegetation types" were expressed as proportions of each farm's total grazed area. In order to reduce the effect of influential observations, all veg- 

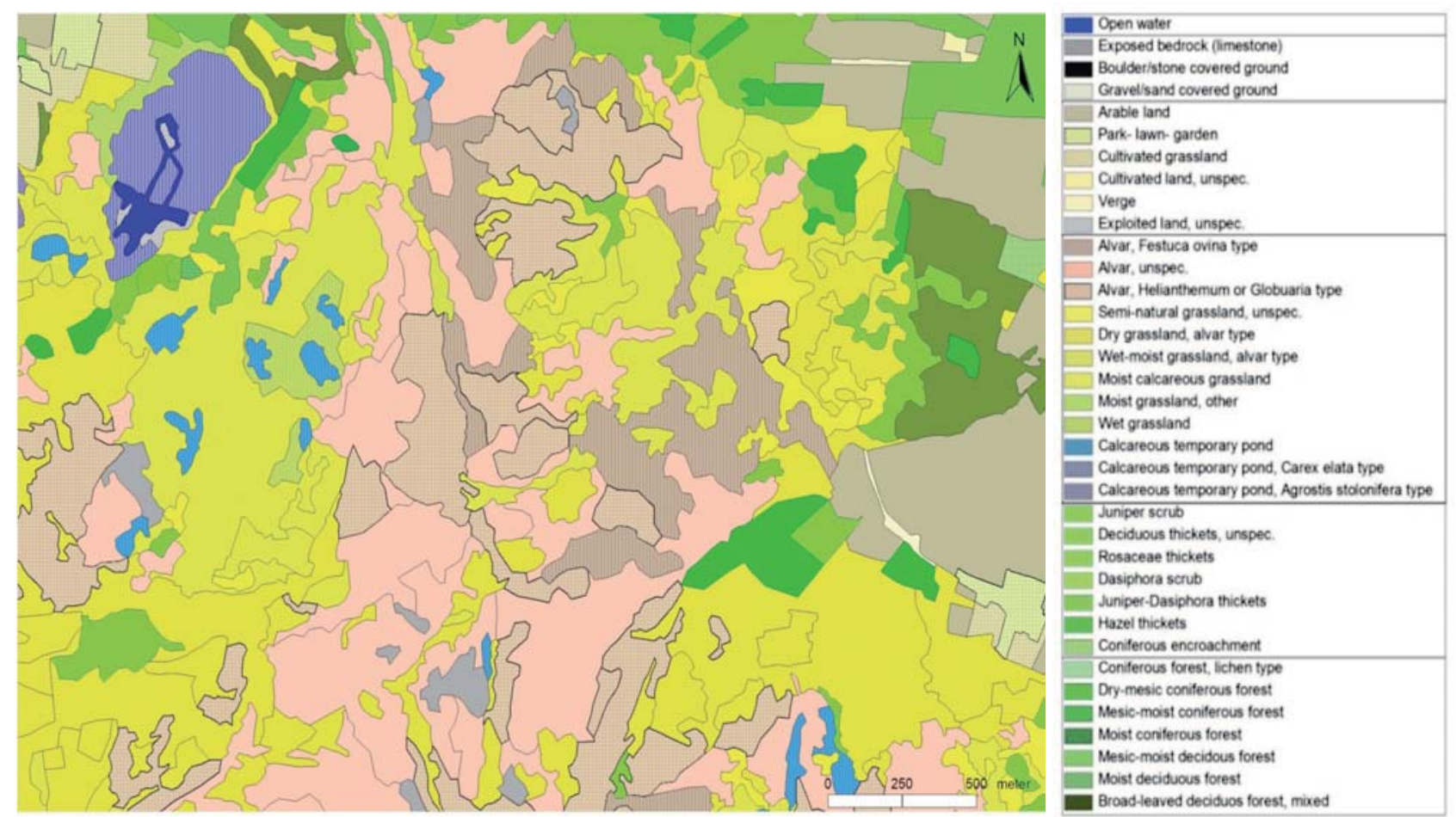

Fig. 1. Section of the vegetation map of the island of Öland (GSD-map $\left.{ }^{\mathrm{TM}}\right)$, SE Sweden, showing examples of vegetation types in six different landscape types that occur on the island. The landscape types are (from top) "surface water", "exposed ground", "cultivated/exploited land", "open dwarf shrub or herbaceous vegetation", "scrub vegetation/thicket" and "forest".

etation proportions were $4^{\text {th }}$-root-transformed prior to analysis. All significant patch "vegetation types" in the additive regression model for each resolution are represented in Table 1, which shows all three spatial levels of patch resolution to allow for comparison between scales within "vegetation types", as well as among "vegetation types" within spatial scales. The full models were reduced by a backward elimination procedure of insignificant variables using Akaike's information criterion (AIC) (Crawley, 2007), and adjusted $\mathrm{R}^{2}$ to select the simplest, most informative model. All non-significant "vegetation types" were omitted from Table 1, except when included in any of the other regression models.

\section{Results}

The D. dendriticum surveillance in slaughtered cattle, obtained from the Kalmar county abattoir, shows that the mean prevalence of the parasite on the island of Öland has gradually increased from $7.2 \%$ in the year 2000 to $11.8 \%$ in 2009 , the latter number more than twice the prevalence $(5.2 \%)$ in the whole country that year (Swedish Animal Health Service, unpublished data). The analysis of all farms that delivered more than 10 animals per year in 2007 showed that the prevalence varied from farms completely free of infection to $92 \%$ in the most severely affected farm. There was no obvious spatial distribution pattern in parasite prevalence between farms.

Relationship between the prevalence of $\mathrm{D}$. dendriticum and vegetation

The relationship between vegetation and prevalence of D. dendriticum in cattle stocks on Öland was analysed at three different levels of patch resolution (Table 1).

\section{Landscape type}

This, the most coarse-grained scale of patch classification, explained $27 \%$ of the variance in angular transformed prevalence of $\mathrm{D}$. dendriticum $(\mathrm{Pa})$. The relationship was estimated by the regression equation:

$$
P a=0.377-0.504 W^{0.25}-0.251 C^{0.25}+0.312 F^{0.25}
$$

where $W, C$ and $F$ are the areal proportions of surface water, cultural/exploited land, and forests, respectively. All three variables were significant $(\mathrm{P}<0.01)$ and surface water $(W)$ had the largest negative effect on prevalence as shown by the regression coefficients, while forests $(F)$ exhibited a positive effect. 
Table 1. Regression coefficients and significance levels for patch vegetation types explaining the prevalence of Dicrocoelium spp. in cattle stocks at Öland, Sweden. The result from the three different multiple regressions presented in the three columns to the left. Explanatory variables are presented at three different levels: landscape types (NT), main vegetation types (HV) and vegetation types (VT).

\begin{tabular}{|c|c|c|c|c|c|}
\hline & Final mode & & 0.001 & 0.001 & 0.001 \\
\hline & Final model ad & & 0.268 & 0.360 & 0.423 \\
\hline Explanat & $\operatorname{les}^{a}$ & Occurrence $^{b}$ & NT & HV & VT \\
\hline Code & Patch type & (N) & Coefficient & Coefficient & Coefficient \\
\hline NT100 & Surface water $(W)$ & 124 & $-0.504 * * *$ & & \\
\hline HV110 & Open water $\left(\mathrm{W}_{\mathrm{O}}\right)$ & 123 & & $-0.438 * * *$ & \\
\hline VT111 & Shallow water $\left(\mathrm{W}_{\mathrm{Os}}\right)$ & 68 & & & $-0.258 * *$ \\
\hline NT200 & Exposed ground & 103 & ns & & \\
\hline HV220 & Boulder/stone covered ground $\left(\mathrm{E}_{\mathrm{B}}\right)$ & 26 & & $0.516^{* * *}$ & \\
\hline VT220 & Boulder/stone covered ground $\left(\mathrm{E}_{\mathrm{Bb}}\right)$ & 26 & & & $0.424 * *$ \\
\hline NT300 & Cultivated/exploited land $(C)$ & 201 & $-0.251 * *$ & & \\
\hline HV310 & Cultivated land $\left(\mathrm{C}_{c}\right)$ & 200 & & ns & \\
\hline VT311 & Arable land $\left(\mathrm{C}_{\mathrm{Ca}}\right)$ & 197 & & & $-0.191 * *$ \\
\hline VT313 & Verge $\left(\mathrm{C}_{\mathrm{Cv}}\right)$ & 137 & & & $0.323 *$ \\
\hline HV330 & Exploited land CE & 77 & & ns & \\
\hline VT330 & Exploited land, unspec. $\left(\mathrm{C}_{\mathrm{Ee}}\right)$ & 54 & & & $-0.556 * *$ \\
\hline NT400 & Open dwarf shrub or herbaceous vegetation & 201 & ns & & \\
\hline HV440 & Semi-natural grasslands & 201 & & ns & \\
\hline VT441 & Dry grassland & 106 & & & $0.127 * *$ \\
\hline HV450 & Littoral (seminatural) grasslands & 103 & & ns & \\
\hline VT451 & Moist freshwater grassland & 20 & & & $-0.286^{*}$ \\
\hline NT500 & Scrub vegetation/thicket $(S)$ & 145 & ns & & \\
\hline HV530 & Mixed thickets $\left(\mathrm{S}_{\mathrm{M}}\right)$ & 39 & & $0.350 * * *$ & \\
\hline VT531 & Juniper-Dasiphora thickets $\left(\mathrm{S}_{\mathrm{Mj}}\right)$ & 39 & & & $0.419 * * *$ \\
\hline NT600 & Forest $(F)$ & 170 & $0.312^{* * * *}$ & & \\
\hline HV730 & Deciduous forest, bryophyte type $\left(\mathrm{F}_{\mathrm{D}}\right)$ & 96 & & ns & \\
\hline VT737 & Moist deciduous forest $\left(\mathrm{F}_{\mathrm{Dm}}\right)$ & 46 & & & $-0.313 * *$ \\
\hline HV760 & Mixed deciduous forest $\left(\mathrm{F}_{\mathrm{M}}\right)$ & 97 & & $0.363 * * *$ & \\
\hline VT760 & Mixed deciduous forest, unspec. $\left(\mathrm{F}_{\mathrm{Mm}}\right)$ & 97 & & & $0.429 * * *$ \\
\hline NT800 & Open mire $(M)$ & 95 & ns & & \\
\hline HT860 & Magnocaricetum mire (tall sedges, $\mathrm{M}_{\mathrm{M}}$ ) & 45 & & ns & \\
\hline VT860 & Magnocaricetum mire $\left(\mathrm{M}_{\mathrm{Mm}}\right)$ & 45 & & & $-0.174 *$ \\
\hline HV870 & Shrub dominated fen $\left(\mathrm{M}_{\mathrm{S}}\right)$ & 3 & & ns & \\
\hline VT871 & Willow fen $\left(\mathrm{M}_{\mathrm{S}_{\mathrm{w}}}\right)$ & 3 & & & $0.585^{*}$ \\
\hline
\end{tabular}

a The multiple regressions are performed with $4^{\text {th }}$ root transformed areal proportions of patch types as explanatory variable and the angular transformation of prevalence of Dicrocoelium spp. in cattle stocks as response variable; ${ }^{\mathrm{b}}$ Occurrence is the number of farms with the patch type. $\mathrm{ns}=\mathrm{P}>0.05 ; * \mathrm{P}<0.05 ; * * \mathrm{P}<0.01 ; * * \mathrm{P}<0.001$

\section{Main vegetation type}

The medium scale investigated explained $36 \%$ of the variance in the angular transformed prevalence of D. dendriticum. The relationship was estimated by:

$$
\begin{gathered}
P a=0.221-0.438 W_{O}^{0.25}+0.516 E_{B}^{0.25}+ \\
+0.350 S_{M}^{0.25}+0.363 F_{M}^{0.25}
\end{gathered}
$$

where main vegetation types from two additional landscape types exhibit significant effects, i.e. "boulder or stone" $\left(\mathrm{E}_{\mathrm{B}}\right)$ within "exposed ground" $(\mathrm{E})$ and "mixed thickets" $\left(S_{M}\right)$ within "scrub vegetation" (S).
Open water $\left(W_{O}\right)$ showed a negative effect on prevalence, while mixed deciduous forests $\left(F_{M}\right)$ was positive. As seen in table 1, all four "main vegetation types" are highly significant $(\mathrm{P}<0.001)$ but the impacts of cultivated/exploited land and semi-natural grasslands were not significant (Table 1). At the "main vegetation type" scale, boulders or stones $\left(E_{B}\right)$ had the largest positive effect on prevalence.

\section{Vegetation type}

The most fine-grained scale explained the most of the variance in the angular transformed prevalence of Dicrocoelium spp. $(42 \%)$. At this scale, "vegetation 
types" from two additional "landscape types" (Table 1) contributed to the explanatory model. The relationship was estimated by:

$$
\begin{gathered}
P a=0.222-0.258 W_{O s}^{0.25}+0.424 E_{B b}^{0.25}- \\
-\left(0.191 C_{C a}^{0.25}-0.323 C_{C v}^{0.25}+0.556 C_{E e}^{0.25}\right)+ \\
+\left(0.127 O_{S d}^{0.25}-0.286 O_{L m}^{0.25}\right)+0,419 S_{M j}^{0.25}- \\
-\left(0.313 F_{D m}^{0.25}-0.429 F_{M m}^{0.25}\right)- \\
-\left(0.174 M_{M m}^{0.25}-0.585 M_{S w}^{0.25}\right)
\end{gathered}
$$

where the areal proportion of shallow open water $\left(W_{O s}\right)$ showed a significantly negative relationship, whereas ground covered by boulders and/or stones $\left(E_{B b}\right)$ and areas of Juniperus-Dasiphora thicket $\left(S_{M_{j}}\right)$ both had a significantly positive relationship with the prevalence $(\mathrm{Pa})$.

Among the cultivated/exploited "vegetation types", two exhibited a significantly negative relationship, i.e. arable land $\left(C_{C a}\right)$ and exploited land $\left(C_{E e}\right)$, while one (verge vegetation) was significantly positive $\left(C_{C v}\right)$. Contrasting relationships were also found among vegetation types of open semi-natural grasslands, forests and open mires. Dry grasslands $\left(\mathrm{O}_{S d}\right)$ showed a positive relationship, while moist freshwater grasslands $\left(O_{L m}\right)$ were negative. Similarly, moist deciduous forests $\left(F_{D m}\right)$ showed a significantly negative relationship, while the dryer mixed deciduous forests $\left(F_{M m}\right)$ were significantly positive. Among mires, the magnocaricetum type consisting of tall sedge fens $\left(M_{M m}\right)$, were negatively related, while willow fen areas $\left(_{M S w}\right)$ were positively related to the angular transformed prevalence of D. dendriticum $(\mathrm{Pa})$.

Relationship between the prevalence of $\mathrm{D}$. dendriticum and soil types (quaternary deposits)

Regression analysis of soil types as explanatory variables resulted in a model that explained $10 \%$ of the variance in the angular transformed prevalence of D. dendriticum:

$$
P a=0.292-2.57 O_{W}+6.078 G_{w-v}
$$

where $O_{W}$ is the areal proportion of open water and $G_{w-v}$ represents wave-washed sediments, gravel with thin surface layer of peat (Anova; $\mathrm{F}_{2,200}=12.69$, $\mathrm{P}<0.001$, adj. $\left.\mathrm{R}^{2}=0.104\right)$.

\section{Discussion}

Several studies have contributed to our current knowledge on the distribution of dicrocoeliasis and provided information on symptoms and host responses of infected animals (Otranto and Traversa, 2002). However, at the regional and local landscape scale, little is known about the role of different landscape patches with regard to the risk for $D$. dendriticum infection for grazing ruminants. In this study, we found that a number of different vegetation types significantly contribute, positively or negatively, to parasite prevalence. This suggests that risk habitats for dicrocoeliasis in grazing ruminants can be identified using multiple regression models. We also found that risk habitats can be hidden at larger scales by the contrasting effects among fine-grained landscape patches.

The regression analyses were performed at three levels of resolution. At the largest scale, forest areas was the only patch type that increased the parasite prevalence $(\mathrm{P}<0.001)$, whereas "surface water" ( $\mathrm{P}$ $<0.001)$ and "cultivated/exploited land" $(\mathrm{P}<0.01)$ significantly decreased the prevalence. The mean coverage in grazed areas of the forest landscape type was only $7.9 \%$. However, at the medium patch scale the presence of forests also increased parasite prevalence significantly. The main vegetation type, i.e. "mixed deciduous forest" and the vegetation type "mixed deciduous forest, unspecific" both positively contributed to increased prevalence of D. dendriticum ( $\mathrm{P}$ $<0.001)$. Interestingly, a more than 40 years old Swedish study (Bengtsson et al., 1968) noted that cattle from farms situated in forest districts generally had two to three times higher prevalence of $D$. dendriticum compared to cattle from open, non-forested areas. Their explanation was that the intensively cultivated areas on the plains provided inferior habitats for the intermediate mollusk hosts compared to the forest districts characterised by more uncultivated areas and permanent pastures. Trees and shrubs are important for both diversity and abundance of land snails in three different ways (von Proschwitz, 2010). First, a predominantly woody landscape character provides protection against grazing animals; second, the shading effect of the canopy is important for the sun- and drought-sensitive snails; and third, the leaves of broad-leaved deciduous trees accumulate calcium citrate, which is easily soluble and available for snails.

The landscape type "shrub vegetation/thicket" did not significantly affect the prevalence of $D$. dendriticum. However, at the more fine-grained scale the main vegetation type "mixed thickets" and the vege- 
tation type of "Juniper-Dasiphora thickets" both contributed positively to parasite prevalence $(\mathrm{P}<0.001)$, suggesting that these vegetation types are favourable habitats for D. dendriticum and their hosts. For the landscape type of "exposed ground" the models suggest that both the "main vegetation type" of "boulder/stone-covered ground" and the "vegetation type" with the same name have positive effects on the parasite prevalence. The landscape type of "open dwarf shrub or herbaceous vegetation" contained one vegetation type, i.e. that of "dry grassland", suggested by the model to increase parasite prevalence, whereas "moist freshwater grassland" was suggested to decrease parasite prevalence. These findings are well in line with previous studies suggesting that $D$. dendriticum are connected with dry pastures (Otranto and Traversa, 2003). The negative relationship with parasite prevalence, found for "moist freshwater grassland", "moist deciduous forest" as well as for "magnocaricetum mire", indicate that wet areas present a low risk for D. dendriticum infection of cattle, corroborating earlier findings (Otranto and Traversa, 2003). A likely explanation is that most ant species shun wet habitats, which also explains the less surprising negative relationship between "open water" and parasite prevalence. However, the vegetation type "willow fen" was an exception being positively correlated with $D$. dendriticum prevalence. Salix spp. are shown to be favoured habitats for land snails in fens (von Proschwitz, 2009, 2010) and this might also be the case for ants.

"Cultivated/exploited" land was negatively correlated to parasite prevalence at the "landscape type" level as well as at the "vegetation type" level ("arable land" and "exploited land, unspecific"). The exception was "verge" that contributed positively to parasite prevalence in the model. In general, parasites with complex life cycles are suggested to decline with a decrease in biodiversity (Lafferty and Kuris, 2005). Frequent disturbances and low species richness characterise the landscape type of cultivated/exploited land. Negative effects of soil disturbances are shown both for ants (Graham et al., 2004) and for mollusks (Stiven, 1989). In contrast, verges usually have an intact grass sward, and can provide microhabitats for many ant species (Samways et al., 1997).

\section{Conclusion}

Habitats at risk for transmission of D. dendriticum to grazing cattle may be identified by combining data on parasite prevalence with landscape data. The presence of forest growth in pastures significantly increase parasite prevalence throughout all spatial scales analysed in this study, and hence can be regarded as a strong risk factor for D. dendriticum transmission to cattle. Generally, the presence of wet areas significantly decrease parasite prevalence, suggesting that $D$. dendriticum intermediate hosts are less abundant in wet habitats.

The model used in this study provides a systematic and relatively easy tool to identify risk habitats for parasite infection of ruminants. Although further studies in the field are needed to confirm such findings, we believe that the model is a rational first step, and could be applied to other parasites with similar life cycles such as Fasciola hepatica.

\section{Acknowledgements}

Statistics from surveillance of $D$. dendriticum in slaughtered animals were kindly provided by the Kalmar county abattoir (KLS Ugglarps) and the Swedish Animal Health Service. Data on grazing areas were kindly provided by the county board administration in Kalmar. We thank Charlotte Hallén Sandgren, Anders Andersson and Helena Lager for valuable support.

\section{References}

Bengtsson E, Hässler L, Holtenius P, Nordbring F, Thorén G, 1968. Infestation with Dicrocoelium dendriticum - the small liver fluke - in animals and human individuals in Sweden. Acta Path Microbiol Scandinav 74, 85-92.

Chartier C, Reche B, 1992. Gastrointestinal helminths and lungworms of French dairy goats: prevalence and geographical distribution in Poitou-Charentes. Vet Res Commun 16, 327-335.

Crawley MJ, 2007. The R Book. John Wiley \& Sohns Ltd, Chichester, UK.

Cringoli G, Rinaldi L, Veneziano V, Capelli G, Malone JB, 2002. A cross-sectional coprological survey of liver flukes in cattle and sheep from an area of the southern Italian Apennines. Vet Parasitol 108, 137-143.

Forman RTT, 1995. Land Mosaics: The Ecology of Landscapes and Regions. Cambridge University Press, Cambridge, UK.

Graham JH, Hughie HH, Jones S, 2004. Habitat disturbance and the diversity and abundance of ants (Formicidae) in the Southeastern Fall-Line Sandhills. J Ins Sci 4, 1-15.

Lafferty KD, Kuris AM, 2005. Parasitism and environmental disturbances. In: Parasitism and Ecosystems (F Thomas, JF Guégan \& F Renaud eds). Oxford University Press, Oxford, UK, pp. 113-122.

Lantmäteriet, 2009. Kvalitetsbeskrivning för GSDVegetationsdata. In GSD Geografiska SverigedataTM. Gävle: 
Lantmäteriet.

Manga-Gonzalez MY, Gonzalez-Lanza C, Cabanas E, Campo $\mathrm{R}, 2001$. Contributions to and review of dicrocoeliosis, with special reference to the intermediate hosts of Dicrocoelium dendriticum. Parasitology 123, S91-114.

Musella V, Catelan D, Rinaldi L, Lagazio C, Cringoli G, Biggeri A, 2011. Covariate selection in multivariate spatial analysis of ovine parasitic infection. Prev Vet Med 99, 69-77.

Otranto D, Traversa D, 2002. A review of dicrocoeliosis of ruminants including recent advances in the diagnosis and treatment. Vet Parasitol 107, 317-335.

Otranto D, Traversa D, 2003. Dicrocoeliosis of ruminants: a little known fluke disease. Trends Parasitol 19, 12-15.

R Development Core Team, 2010. R: a language and environment for statistical computing. R Foundation for Statistical Computing, Vienna, Austria.

Samways MJ, Osborn R, Carliel F, 1997. Effect of a highway on ant (Hymenoptera: Formicidae) species composition and abundance, with a recommendation for roadside verge width. Biodiv Conserv 6, 903-913.

Sokal RR, Rohlf FJ, 1995. Biometry, 3rd ed. Freeman HW and Company, New York, USA.
Stiven AE, 1989. Population biology of two land snails (Mesomphix spp.): variation among six southern Appalachian sites with differing disturbance histories. Oecologia 79, 372382.

Wallner F, 1999. Vegetationskarta över Öland Lantmäteriet (GSD Vegetation map data for the island Öland, SE Sweden). von Proschwitz T, 2009. Landlevande mollusker i rikkärr i Västmanlands län. [English summary, p. 6: Land-snails in rich fens in the province of Västmanlands län (C. Sweden), with comments on the species and recommendations of conservation measures for the investigated objects]. In Rapport 2009:28 Inventeringar 2007-2008 samt skötselrekommendationer med särskild hänsyn till molluskfaunan: Länsstyrelsen Västmanlands län.

von Proschwitz T, 2010. Inventering av snäckor i rikkärr på Gotland 2006. [English summary, pp. 71-72: Land-snails in rich fens in the province of Gotlands län (E. Sweden), with special reference to occurrences of Cochlicopa nitens (M. von Gallenstein) and Vertigo geyeri Lindholm, and recommendations of conservation measures for the investigated objects 2006]. In Rapporter om natur och miljö, pp. 82: Länsstyrelsen i Gotlands län. 